\title{
Pengaruh Bauran Pemasaran Pada Penjualan Cerutu PT BIN Di Indonesia
}

\author{
Musaiyadi \\ Sekolah Tinggi Ilmu Ekonomi Mandala
}

\begin{abstract}
This paper aim to analyze how so far the effect of marketing mix toward total sale of BIN's cigars in local market. By using mountly data from 2016.1 to 2018.12 on error correction model, this research finds out: (1) product varian of BIN's cigars significant statistically influence total sale of BINs cigars in local market positively. (2) average price of BIN's cigars statistically influences total sales of BIN's cigars in local market negatively. (3) promotion costs of BIN's cigars statistically did'nt influences total sales of BIN's cigars in local market negatively. (4) distribution channels of BIN's cigars statistically did'nt influences total sales of BIN's cigars in local market negatively. (5) All of those independent variables significant statistically and simultaneously influences total sales of BIN's cigars in local market positively.
\end{abstract}

Keywords: Marketing, Mix Strategy, Cigars

\section{Pendahuluan}

PT Boss Image Nusantara (BIN) adalah sebuah perusahaan cerutu Jember berdiri sejak tahun 2016 dengan tingkat penjualan yang sangat tinggi. Disamping menjual produk di pasar dalam negeri, cerutu ini juga dipasarkan ke luar negeri. Ekspor BIN terbesar adalah ke Cina, dan pangsa pasar lainnya adalah Turki, Polandia, Moldova, Malaysia, Amerika dan Siprus. Sebagai salah satu industri yang bergerak dibidang cerutu, BIN membawa manfaat yang cukup besar diantaranya menyerap tenaga kerja dan membuka lapangan kerja baru sehingga sedikit banyak meningkatkan PAD Kabupaten Jember. Tahun 2018 BIN sudah dapat memproduksi sebanyak 140.065 batang dengan tenaga kerja sebanyak 30 orang yang mayoritas wanita. Ada tiga jenis cerutu yang diproduksi di PT BIN yakni cerutu berbatang pendek (small cigar), sedang (soft filler), dan panjang (long filler). Tahun 2018 omset penjulan mereka sudah mencapai 2.6 M, dan telah berhasil masuk ke salah satu deretan produsen rokok cerutu terbaik dunia. 
Motivasi dari penelitian ini didorong oleh konsep bisnis yang menyatakan bahwa keberhasilan perusahaan memprogram strategi pemasaran berdampak pada meningkatnya penjualan. Penjulan produk perusahaan sangat bergantung pada selera konsumen. Tipologi dari masing-masing konsumen tidak sama, sehingga profil dan prefensi masing-masing konsumen harus dipahami oleh perusahaan. Dari latar belakang di atas, tujuan dari tulisan ini untuk menjawab: variabel apa saja dalam bauran pemasaran (marketing mix) secara signifikan mempengaruhi nilai total penjualan cerutu BIN di pasar lokal atau Indonesia.

Tulisan ini menggunakan data primer dan data sekunder dari laporan keuangan perusahaan. Data dianalisis dengan metode regresi dengan menggunakan model koreksi kesalahan. Setelah hasil regresi diperoleh, langkah selanjutnya dalam tulisan ini adalah manganalis hubungan variabel yang dimaksud. Teori strategi pemasaran yang harus dilakukan BIN guna memperoleh penjualan yang tinggi di pasar lokal akan dikaji dalam pembahasan selanjutnya.

Temuan dari penelitian ini menunujukan bahwa jumlah varian produk berpengaruh positif dan signifikan, harga rata-rata cerutu berpengaruh negatif dan signifikan, sedangkan jumlah saluran distribusi dan biaya promosi tidak berpengaruh secara signifikan terhadap penjualan cerutu BIN di Indonesia. Dengan mengetahui hasil ini, perusahaan dapat menambah jumlah varian produk dan menaikkan harga produk untuk meningkatkan profit karena nilai koefisien harganya inelastik. Tulisan ini dibagi ke dalam lima bagian. Pertama adalah pendahuluan. Bagian kedua adalah profil BIN. Bagian ketiga adalah studi literatur. Bagian ke empat adalah metodologi penelitian dan hasil analisis. Dan bagian terakhir adalah simpulan dan rekomendasi.

\section{PROFILE PT BOS IMAGE NUSANTARA (BIN)}

Jember terkenal dengan tembakaunya yang bernama Besuki Na Oogst (BNO), suatu jenis daun tembakau yang digunakan untuk membuat cerutu. Tradisi cerutu Indonesia berasal dari Belanda. Tak jelas apa dan siapa pabrik cerutu pertama di Hindia Belanda. Berdasarkan penelusuran sejarah, lebih dari dua abad lamanya tembakau BNO tumbuh di Jember. George Bernie adalah orang pertama yang mendapatkan hak erfpacht atau hak guna usaha pertama untuk jangka waktu 75 
tahun menggarap arela perkebunan untuk menanam tembakau jenis BNO. PTPN XII adalah salah satu BUMN yang melakukan budidaya BNO Jember telah mengekspor ke beberapa negara di Eropa (Bremen), Asia, dan Amerika. Daun tembakau BNO dimanfaatkan terutama untuk bahan pembalut cerutu (dekblad), bahan pengikat (binder) dan pengisi (filler). Tembakau dari Jember ini tidak kalah dengan daun tembakau cerutu terkenal dari Kuba maupun Amerika.

Melihat peluang bisnis cerutu yang menjanjikan, ditambah dengan ketersediaan luas area lahan perkebunan dan pertanian di Jember, memberikan daya tarik bagi BIN untuk menanam tembakau BNO karena produk ini berorientasi ekspor. Tidak hanya itu, tingginya harga cerutu mendorong perusahaan untuk membuat pabrik cerutu di Jember. BIN didirikan oleh H. Abd. Kahar Muzakir bersama dua rekannya pada tahun 2016. Saat ini perusahaan BIN dipimpin oleh Bapak H. Agusta Jaka Purwana MM. BIN berlokasi di Jalan Brawijaya No. 5 Jubung Jember Jawa Timur.

BIN mempunyai spesifikasi produk sangat unik yaitu menggunakan bahan tembakau dari hasil tanam sendiri dengan varietas yang spesifik yaitu berasal dari negara Cuba yang telah teraklimatisasi di Indonesia selama 20 tahun sehingga menyamai taste aslinya. Ditanam di tanah vulcano sehingga menimbulkan taste dan aroma yang sesuai. Begitu juga pengolahan mulai dari fermentasi sampai sortasi bahan baku cerutu dilakukan dengan tenaga kerja yang profesional. Untuk memperoleh citarasa produk yang konsisten, BIN menerapkan beberapa kebijakan yang meliputi: kebijakan lingkungan, kebijakan mutu, dan kebijakan keselamatan dan kesehatan kerja.

Kebijakan Lingkungan (environmental policy). BIN membuktikan bahwa kegiatan perusahaan dengan menggunakan bahan baku tembakau yang ditanam sendiri adalah salah satu bentuk nyata sangat peduli terhadap kelestarian lingkungan. Kebijakan tersebut mencakup:

- Dalam aktivitas proses produksinya, mengunakan pestisida yang ramah lingkungan dan terkontrol untuk mencegah dampak negatif terhadap kelestarian lingkungan, 
- Melaksanakan, menjaga, memperbaiki dan selalu menyempurnakan Sistem Manajemen Lingkungan yang dimiliki secara berkesinambungan serta mengkomunikasikan kepada seluruh karyawan,

- Memonitoring kondisi lingkungan secara terus menerus dan berusaha untuk mematuhi peraturan-peraturan pemerintah yang berlaku baik lokal maupun nasional serta berusaha memenuhi standar lingkungan internasional,

- Selalu berusaha dan mengkaji ulang untuk mencapai target dan tujuan pelestarian lingkungan sesuai dengan upaya yang telah ditetapkan,

- Kebijakan lingkungan ini merupakan komitmen manajemen dan seluruh karyawan BIN dan terbuka untuk umum.

Kebijakan Mutu (quality policy). Tuntutan mutu adalah hal yang paling utama untuk saat ini disamping masalah lingkungan. Persaingan pasar yang sangat ketat baik di pasar lokal maupun di pasar internasional, mendorong BIN selalu berusaha semaksimal mungkin meningkatkan dan menjaga mutu produk secara konsisten untuk menghasilkan cerutu dengan kualitas premium. Kebijakan BIN terhadap mutu produk mencakup:

- Secara konsisten memenuhi spesifikasi dan persyaratan yang diminta oleh pelanggan dengan harga bersaing melalui sistem kerja yang efisien dan efektif,

- Melakukan penyempurnaan secara terus menerus pada produksi yang dihasilkan serta mengkomunikasikan dengan seluruh karyawan,

- Penerapan quality control pada tiap tahapan proses produksi,

- Memprioritaskan kepuasan pelanggan dengan menjaga kualitas produk, harga dan pengiriman tepat waktu.

Kebijakan Keselamatan dan Kesehatan Kerja (safety and helath work policy).

Kebijakan BIN terhadap keselamatan dan kesehatan kerja adalah sebagai berikut:

- Dalam aktivitas produksinya, sistem organisasi dan manajemen dilakukan secara berkesinambungan serta mematuhi pelaksanaan undang-undang atau peraturanperaturan keselamatan dan kesehatan kerja,

- Merencanakan, melaksanakan, memonitor, menyempurnakan sistem manajemen keselamatan dan kesehatan kerja bagi seluruh karyawan serta pencegahan terhadap kejadian yang dapat menimbulkan kerugian baik 
menyangkut manusia maupun harta milik Perusahaan sebagai akibat suatu kecelakaan,

- Seluruh karyawan BIN wajib memahami, menghayati dan menerapkan ketetapan tentang keselamatan dan kesehatan kerja dalam kegiatan sehari-hari di unit kerja masing-masing serta berkewajiban memelihara dan menciptakan lingkungan kerja yang ringkas, rapi, bersih dan terawat,

- Kebijakan keselamatan dan kesehatan kerja ini merupakan komitmen seluruh karyawan dan manajemen Boss Image Nusantara.

\section{Produk Cerutu Bin}

Boss Image Nusantara telah berhasil memproduksi cerutu dengan berbagai varian produk seperti pada tabel 1 berikut:

\section{$\underline{\text { Tabel 1. Jenis Produk dan Daftar Harga Cerutu BIN } 2018}$}

\begin{tabular}{|c|c|c|c|c|c|c|c|c|}
\hline No. & $\begin{array}{l}\text { Product } \\
\text { Code }\end{array}$ & Mark & Type & Qty/pack & Diameter & Length & Packing & $\begin{array}{l}\text { Price } \\
\text { IDR }\end{array}$ \\
\hline 1 & BR10 & BOSLUCKS & Robusto & 10 & 50 & $4^{\prime \prime} 7 / 8$ & Wooden & 540,000 \\
\hline 2 & BR3 & BOSLUCKS & Robusto & 3 & 50 & $4^{n} 7 / 8$ & Paper & 165,000 \\
\hline 3 & BC10 & BOSLUCKS & Corona & 10 & 48 & $5^{n} 1 / 2$ & Wooden & 500,000 \\
\hline 4 & BC5 & BOSLUCKS & Corona & 5 & 48 & $5^{n} 1 / 2$ & Paper $:=$ & 250,000 \\
\hline 5 & BC1T & BOSLUCKS & Corona & $1+*$ & 48 & $5^{\prime \prime} 1 / 2$ & Cello & 54,000 \\
\hline 6 & BHC10 & BOSLUCKS & Half Corona & 10 & 34 & $5^{\prime \prime}$ & Wooden & 450,000 \\
\hline 7 & BHC5 & BOSLUCKS & Half Corona & 5 & 44 & $5^{n}$ & Paper & 250,000 \\
\hline 8 & BHC1T & BOSLUCKS & Half Corona & 2 & 44 & $5^{\prime \prime}$ & Tube & 110,000 \\
\hline 9 & M10 & Maumere & Half Corona & 10 & $44^{\circ}$ & $5^{\prime \prime}$ & Wooden & 450,000 \\
\hline 10 & M5 & Maumere & Half Corona & 5 & 44 & $5^{n}$ & Paper & 250,000 \\
\hline 11 & M1T & Maumere & Half Corona & 1 & 44 & $5^{\prime \prime}$ & Tube & 110,000 \\
\hline 12 & DA10 & Don Agusto & Robusto & 10 & 54 & $5 " 7 / 8$ & Wooden & $1,500,000$ \\
\hline 13 & DA5 & Don Agusto & Robusto & 5 & 54 & $5 " 7 / 8$ & Wooden & 750,000 \\
\hline 14 & BE20CL & BIN Exclusive & Mix & 20 & Mix & Mix & Wooden & $4,500,000$ \\
\hline 15 & BCOLL24 & Boss Collection & Mix & 24 & Mix & Mix & Wooden & $1,000,000$ \\
\hline 16 & BCOLL16 & Havana Collection & Mix & 16 & Mix & Mix & Wooden & 800,000 \\
\hline 17 & JC15 & Jember Cigar & Torpedo & 15 & 41 & $5^{\prime \prime} 1 / 8$ & Wooden & 450,000 \\
\hline 18 & $\mathrm{JC} 12$ & Jember Cigar & Torpedo & 12 "Lighter & 41 & $5 " 1 / 8$ & Wooden & 450,000 \\
\hline 19 & CM16 & Cigar Master & Medium & 16 & 30 & 4" $1 / 2$ & Wooden & 187,000 \\
\hline 20 & EN20 & El Nino & Medium & 20 & 27 & $4^{\prime \prime} 1 / 8$ & Wooden & 224,000 \\
\hline 21 & EN5 & El Nino & Medium & 5 & 27 & $4 " 1 / 8$ & Paper Pack & 27,000 \\
\hline 22 & $\mathrm{C} 16$ & C99 & Medium & 16 & 33 & $4^{\prime \prime}$ & Wooden & 187,000 \\
\hline 23 & C2O & C99 & Medium & 20 & 33 & $4^{\prime \prime}$ & Acrilic & 300,000 \\
\hline 24 & MD20 & Mondlicht & Mini & 20 & 20 & $3^{n} 1 / 2$ & Wooden & 75,000 \\
\hline 25 & MD20 & Mondlicht & Mini & 20 & 20 & $3^{n} 1 / 2$ & Paper Pack & 32,000 \\
\hline 26 & MB10 & Merubetiri & Mini & 10 & 22 & $3 " 1 / 2$ & plat & 40,000 \\
\hline 27 & 2124 & 212 & Medium & 4 & 33 & $4 " 3 / 8$ & Paper Pack & 22,000 \\
\hline 28 & NFCG4 & NFC & Medium & 4 & 33 & 4"3/8 & Paper Pack & 22,000 \\
\hline & NFCR4 & NFC & Medium & 4 & 33 & $4^{\prime \prime} 3 / 8$ & Paper Pack & 22,000 \\
\hline
\end{tabular}

Produk cerutu BIN terdiri dari dua kemasan yang menggunakan kemasan 
kotak kayu (wooden box) dan kemasan kotak kertas (paper box). BIN memproduksi dengan berbagai varian cerutu secara terus menerus. Manajemen produksi mencatat bahwa kapasitas produksi untuk cerutu kualitas premium adalah sebagai berikut:

- Boss Image Robusto

- Boss Image Corona

- Boss Image Half Corona

- Boss Image La Nina

- Boss Image El Nino

- Moon Light (Cerutu Kecil)
$=10.000$ Batang/month

$=10.000$ Batang $/$ month

$=10.000$ Batang $/$ month

$=20.000$ Batang $/$ month

$=20.000$ Batang $/$ month

$=20.000$ Batang $/$ month

Sejak berdirinya BIN pada tahun 2016, perusahaan ini mengalami peningkatan penjualan secara menakjubkan. Omset penjualan dari tahun 2016 sebesar Rp. 822.650.000 meningkat menjadi Rp. 1.228.598.232 pada tahun 2017. Pada tahun 2018 penjualan sudah mencapai Rp. 2.614.591.313. Manajemen BIN menargetkan pada tahun 2019 ini penjualan bisa mencapai lebih dari 4 miliyar, sembuah angka pencapaian yang sangat tinggi untuk ukuran unit usaha yang baru berdiri. Pada cakupan pasarnya, market share cerutu BIN juga mengalami perluasan, terutama di pasar Indonesia. Hampir seluruh kota-kota besar di Indonesia seperti Jakarta, Surabaya dan Medan sudah terdapat outlite di beberapa hotel di wilayah tersebut.

Konsentransi pemasaran lokal memang saat ini masih fokus di pulau jawa dan Bali, tapi diwaktu-waktu yang akan datang akan lebih intensif lagi di sumatera kalimantan dan sulawesi. Begitu juga pada aspek promosi BIN sering melakukan promosi pemasaran baik melalui sponsorship pada even-even, dan juga promosi lewat media cetak dan madia sosial seperti facebook istagram line dan media sosial yang lain. BIN mengalokasikan dana untuk mengiklankan produk mereka setiap bulan. Secara ringkas, strategi bauran pemasaran dan segmenting, targeting dan positioning yang dilakukan oleh BIN adalah sebagai berikut:

Tabel 2. Fours Ps BIN di Pasar Lokal

\begin{tabular}{|c|c|c|c|}
\hline \multicolumn{4}{|c|}{ Pasar Lokal } \\
\hline Produk & Harga & Distribusi & Promosi \\
\hline Mass production & Harga ditetapkan & BIN>Agen & Sponsorship pada \\
\hline
\end{tabular}




\begin{tabular}{|l|l|l|l|}
\hline $\begin{array}{l}\text { dan order-driven } \\
\text { production }\end{array}$ & $\begin{array}{l}\text { berdasarakan } \\
\text { biaya produksi }\end{array}$ & $\begin{array}{l}\text { (Hotel/ } \\
\text { Perorangan) } \\
\text { >Konsumen }\end{array}$ & $\begin{array}{l}\text { Evens dan } \\
\text { pameran }\end{array}$ \\
\hline
\end{tabular}

Tabel 3. Segmentasi, Targeting dan Positioning (STP) PT BIN

\begin{tabular}{|c|c|c|}
\hline Segmenting & Targeting & Positioning \\
\hline $\begin{array}{l}\text { 1. Perokok pria dan } \\
\text { wanita } \\
\text { 2. Perokok dengan } \\
\text { semua tingkat } \\
\text { pengasilan }\end{array}$ & $\begin{array}{l}\text { Perokok pria umur } 30 \\
\text { tahun keatas dengan } \\
\text { tingkat ekonomi } \\
\text { menengah }\end{array}$ & $\begin{array}{l}\text { Memposisikan } \\
\text { produknya sebagai } \\
\text { lamabang gaya hidup } \\
\text { kaum pria sukses. }\end{array}$ \\
\hline
\end{tabular}

Kinerja penjualan cerutu PT BIN di pasar lokal tidak selalu stabil dan meningkat dari bulan ke bulan. Penambahan varian produk dan rasa yang diyakni sebagai pemacu dalam meningkatnya penjulan dipasar lokal, dan pengalokasian dana promosi serta perluasan saluran distribusi lewat agen dan hotel tidak mampu menjaga stabilitas dan peningkatan penjualan. Terjadi fluktuasi penjualan tiap bulan, sehingga pihak manajemen BIN mengakui bahwa disamping faktor internal (bauran pemasaran/ 4Ps), faktor-faktor eksternal juga ikut menentukan dan memengaruhi fluktuasi total penjualan cerutu BIN di pasar lokal.

\section{Tinjauan Pustaka}

\section{Pengertian Pemasaran}

Menurut Kotler (2003:9) pemasaran adalah suatu proses sosial dimana individu dan kelompok mendapatkan apa yang dibutuhkan dan ingikan dengan menciptakan, menawarkan dan mempertukarkan produk yang bernilai secara bebas dengan pihak lain. Pemasaran lebih menitik beratkan pada pengetahuan akan kebutuhan pelanggan dan upaya untuk memuaskannya melalui atribut produk yang ditawarkan, karena kepuasan konsumen dipandang sebagai pusat pertumbuhan, laba, dan keamanan serta eksistensi perusahaan.

Menurut Basu Swasta DH dan Irawan (2000:5) pemasaran adalah suatu sistem keseluruhan dari kegiatan bisnis yang ditujukan untuk merencanakan, menentukan harga, mempromosikan, dan mendistribusikan barang atau jasa yang memuaskan kebutuhan baik pada pembeli yang ada maupun pembeli potensial.

Dari dua definisi diatas dapat disimpulkan bahwa pemasaran merupakan aspek penting yang harus dilakukan oleh perusahaan untuk mempertahankan 
kelangsungan bisnisnya sehingga dapat terus berkembang dan memperoleh laba. Disamping pemasaran, berhasil tidaknya tujuan bisnis juga didukung oleh aspek managemen lain meliputi produksi, keuangan, sumber daya manusia, informasi dan tekhnologi dan bidang lainnya. Lebih lanjut, kegiatan pemasaran tidak semata-mata untuk menjual barang atau jasa, namun lebih jauh merupakan aktifitas manusia secara keseluruhan yang ditujukan untuk merencanakan, memproduksi dan mempromosikan serta mendistribusikan barang atau jasa yang dapat memuaskan keinginan dan kebutuhan kastemer saat ini dan akan datang.

\section{a. Konsep Product, Privce, Promotion dan Place}

Bauran pemasaran adalah alat pemasaran yang digunakan untuk mencapai tujuan pemasaran di pasar sasaran yang meliputi item alat pemasaran yakni: product, price, promotion dan place (4Ps). Secara singkat item pada masing-masing bagian 4Ps dapat diliat pada diagram berikut:

Diagram 1. Marketing Mix

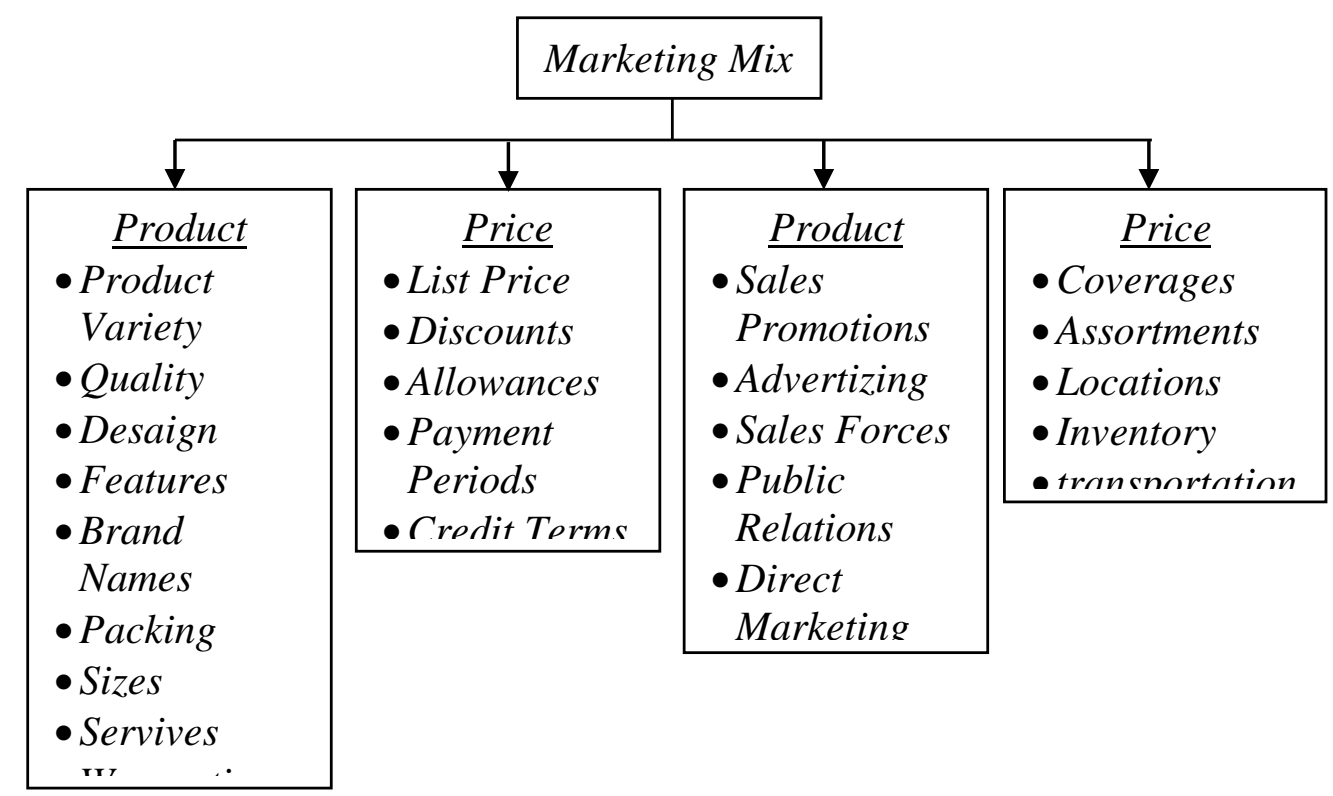

Sumber: Kotler (2000:5) "the four P components of the marketing mix"

Marketing mix adalah kombinasi dari empat variabel atau kegiatan yang merupakan inti dari sistem pemasaran perusahaan yakni product, price, promotion dan place.

\section{a. Product}

Menurut Amstrong dan Kotler (2004:56) produk adalah segala sesuatu yang 
dapat ditawarkan kepada pasar untuk mendapat perhatian, dimiliki, digunakan atau dikonsumsi yang mungkin dapat memuaskan harapan atau kebutuhan. Produk dibagi menjadi dua kelas berdasarkan tipe pelanggan yang mengkonsumsinya sebagai berikut:

1. Produk yang dikonsumsi oleh pelanggan (consumer products)

Produk yang dibeli oleh konsumen akhir sebagai konsumsi pribadi. Produk konsumen ini dibagi menjadi empat bagian yaitu: (1) Produk sehari-hari (convinience product), (2) Produk belanjaan (shopping products), (3) Product khusus (specialty products), (4) Produk yang tidak dicari (unsought products).

2. Produk bagi industri (industrial products)

Produk yang dibeli oleh individu organisasi untuk diproses lebih lanjut atau untuk digunakan sehubungan dengan bisnis. Contohnya bahan mentah atau komponen material.

Produk merupakan elemen yang sangat penting dan menentukan keberhasilan perusahaan. Dalam pengelolaan produk termasuk pula perencanaan dan pengembangan produk/ jasa yang baik untuk dipasarkan oleh perusahaan. Perlu adanya suatu pedoman untuk mengubah produk yang ada, menambah produk baru, atau mengambil tindakan lain yang dapat memengaruhi kebijaksanaan dalam menentukan produk. Selain itu, keputusan-keputusan juga perlu diambil menyangkut masalah pemberian merk, pembungkusan, warna dan produk lainnya.

\section{b. Price}

Menurut Fajar Lasana (2008:105) harga merupakan jumlah uang yang diperlukan sebagai penukar berbagai kombinasi produk dan jasa, dengan demikian maka suatu barang haruslah dihubungkan dengan berbagai macam barang/ atau pelayanan, yang akhirnya akan sama dengan sesuatu yaitu produk atau jasa. Menurut Fandy Tciptono (2001:124) harga adalah satuan moneter agar memperoleh hak kepemilikan atau penggunaan suatu barang atau jasa.

Dalam menentukan suatu harga produk perusahaan dapat ditentukan dengan tiga bentuk strategi, yaitu:

1. Strategi Produk Baru (new product pricing strategies)

Perusahaan yang meluncurkan produk baru mengalami tantangan dalam 
menentukan harga pertama kalinya. Strategi harga produk baru meliputi: (1) market skimming price dan (2) market penetration price

2. Strategi harga bauran produk (product mix pricing strategy)

Strategi untuk menetapkan produk seringkali dapat berubah. Strategi harga bauran produk dibagi menjadi lima bagian meliputi: (1) product line pricing, (2) optimal product pricing, (3) captive produt pricing, (4) by product pricing dan (5) product bundle pricing.

3. Startegi Penyesuaian Harga (price adjustmen strategy)

Perusahaan seringkali menyesuaikan harga dasar mereka untuk setiap konsumen yang berbeda dan situasi yang seringkali berubah. Strategi harga dibagi menjadi enam bagian: (1) discount and allowance pricing, (2) segmented pricing, (3) psycological pricing, (4) promotional pricing, (5) geographical pricing (6) international pricing.

4. Perubahan Harga (price changes)

Setelah mengembangkan strategi dan struktur harga, perusahaan seringkali menghadapi situasi dimana perusahaan harus menetapkan untuk merubah harga atau merespon perubahan harga yang dilakukan pesaing. Perubahan harga tersebut meliputi: (1) initial price change, (2) responding to price change.

5. Kebijakan publik dan penetapan harga (public policy and pricing)

Kompetisi harga adalah elemen utama dalam ekonomi pasar bebas. Dalam menetapkan harga perusahaan harus mempertimbangkan adanya kebijakan dan peraturan yang ditetapkan oleh publik. Kebijakan harga yang ditetapkan oleh publik ini bertujuan untuk mencegah terjadinya monopoli. Dalam kebijkan publik dan penetapan harga dibagi menjadi dua bentuk yaitu: (1). Price within channel levels, (2) price across channel level.

\section{c. Promotion}

Promosi adalah instrumen ke tiga dari marketing mix. Promosi bertujuan untuk memberikan informasi terkait dengan produk yang dijual oleh perusahaan. Menurut Basu Swasta DH (2000:234), komunikasi pemasaran dapat didefinisikan 
sebagai kegiatan komunikasi yang dilakukan pembeli dan penjual dan merupakan pemasaran serta mengarahkan pertukaran agar lebih memuaskan dengan cara menyadarkan semua pihak untuk berbuat lebih baik. Sedangkan promosi merupakan arus informasi satu arah dan hanya dilakukan oleh satu individu atau organisasi tertentu. Ini berbeda dengan komunikasi pemasaran yang tujuannya memuaskan semua pihak.

Menurut Philip Kotler dan Gary Amstrong (2008: 117), terdapat lima sarana promosi yakni (1) Periklanan (advertizing), (2) Promosi penjualan (sales promotion), (3) Hubungan masyarakat (public relation), (4) Penjualan personal (personal selling) dan (5) pemasaran langsung (direct marketing). Masing-masing kategori melibatkan sarana promosi tertentu yang digunakan untuk berkomunikasi dengan konsumen. Contohnya periklanan meliputi penyiaran, media cetak, internet dll. Fungsi dari periklanan adalah (1) memberikan informasi, (2) membujuk/ mempengaruhi (3) menciptakan kesan (image), (4) memuaskan keinginan, dan (5) merupakan alat komunikasi.

\section{d. Place}

Saluran distribusi adalah serangkaian organisasi yang terkait dalam semua kegiatan yang digunakan untuk menyalurkan produk dan status kepemilikan dari produsen ke konsumen. Pengertian ini menunjukkan bahwa perusahaan dapat menggunakan lembaga atau perantara untuk menyalurkan produknya ke konsumen akhir.

Menurut Ronal J. Ebert dan Ricky W. Griffin (2000: 252) distribusi adalah bagian dari marketing mix yang berhubungan dengan mendapatkan produk dari produsen ke konsumen. Ada delapan saluran distribusi utama berdasarkan anggota yang berpartisipasi dalam menyampaikan produk dari produsen ke konsumen yakni: (1) direct distribution of customer product, (2) retail distributon of customer product,(3) wholesale distribution of customer product, (4) distribution through sale agents or brokers, (5) distribution by agents to customers and business, (6) direct distribution of business products (7) wholesale distribution of industrial product, dan (8) wholesale distribution of business ratails. 


\section{Segmenting, Targeting, and Positioning}

Segmenting - Setiap pembeli memiliki keinginan, sumberdaya, lokasi, sikap dalam membeli yang berbeda-beda. Melaui segmentasi pasar, perusahaan membagi pasar menjadi segmen yang lebih kecil yang dapat diraih lebih efisien dan efektif dengan produk dan jasa yang cocok dengan kebutuhan unikpembeli (Pieter Gunawan W, 2017). Adaptasi heterogenitas konsumen yang berbeda tersebut dengan program pemasaran ini penting bagi perusahaan untuk mencapai kesesuaian (fit) antara penawaran produk dengan karakteristik konsumen (Rugman, 1987:342). Segmentasi pasar dapat dilakukan dengan cara menganalisis secara mendalam tentang karakteristik konsumen berdasarkan geograpic, demographic, dan psychografic. Philip Kotler (2003) membagi segmentasi pasar berdasarkan karakteristik konsumen sebagaimana tampak pada Tabel 4 berikut:

Tabel 4. Major Segmentation Variabels for Customer Markets

\begin{tabular}{|l|l|l|l|}
\hline Georaphic & $\begin{array}{l}\text { Region, City or metro } \\
\text { size, Density, and } \\
\text { Climate }\end{array}$ & Psychographic & $\begin{array}{l}\text { Lifestyle } \\
\text { Personality }\end{array}$ \\
\hline Demographic & $\begin{array}{l}\text { Age, Famili size, } \\
\text { Family life cycle, } \\
\text { Gender, Income, } \\
\text { Occupation, } \\
\text { Education, Religion, } \\
\text { Race, Generation, } \\
\text { Nationality, Sosial } \\
\text { class }\end{array}$ & $\begin{array}{l}\text { Occasions, Benefits, } \\
\text { User status, Usage } \\
\text { status, Readiness } \\
\text { stage, and Attitude } \\
\text { toward -product }\end{array}$ \\
& \\
\hline
\end{tabular}

Kotler, Philip, 2003: 288

Setelah segmentasi pasar selesai diindentifikasi, pemasar perlu mencari variabel segmen yang paling dominan mempengaruhi keputusan pembelian produk oleh konsumen. Agar variabel segmentasi tepat (valid) bagi perusahaan, syaratsyarat berikut harus di penuhi, yaitu (Rugman, 1987: 342): (1) segmen harus dapat diukur, (2) segmen harus accessible dan (3) target harus substantial.

Targeting - Target pasar adalah sekumpulan pembeli yang berbagi kebutuhan yang sama atau karakteristik dimana perusahaan putuskan layani. Target pasar mengevaluasi setiap ketertarikan segmen dalam pasar dan memilih satu atau lebih segmen untuk dimasuki (Pieter Gunawan W: 2017). Alternatif target pasar yang akan tersedia bagi pemasar mencakup "ada target" dan "tidak ada target". Apabila 
pilihan yang tersedia adalah "ada target", perusahaan dapat mengambil strategi masuk ke satu atau lebih segmen yang ditargetkan (terkonsentrasi), atau masuk ke semua segmen yang dapat dicover oleh perusahaan (differensiasi). Apabila pilihan yang tersedia adalah "tidak ada target", perusahaan akan keluar dengan sendirinya dari lokasi pemasaran tersebut (Rugman, 1987, h. 334).

Positioning - adalah langkah terakhir yang harus dilakukan oleh seorang pemasar. Tahap ini dilakukan setelah mereka berhasil menemukan target market yang diinginkan. Pemasar harus pintar, terutama pada saat mereka membangun marketing mix programs pada area pasar yang akan dimasuki (Rugman, 1987: 345). Positioning dimana perusahaan menyusun penawaran pasar untuk menempatkan posisi bersaing dengan competitor yang dapat tertanam dibenak konsumen. Langkah deferensiasi dan positioning terdiri dari tiga tahap: (1) mengidentifikasi sekumpulan keunggulan kompetitif yang berbeda dimana untuk membangun posisi, (2) memilih keunggulan kompetitif yang tepat, dan (3) dan memilih strategi positioning secara keseluruhan (Pieter Gunawan W: 2017). Kesalahan dalam melakukan positioning, seringkali menyebabkan kegagalan. Ada empat tipe kegagalan yang sering dialami oleh manager pemasaran berkaitan dengan positioning produk yaitu (Kotler, Philip, 2003, h. 311): under positioning, over positioning, confused positioning, dan doubtful positioning.

\section{Metodologi Penelitian}

\section{Deskripsi Data}

Penelitian ini menggunakan data primer, diperoleh dari laporan keuangan perusahaan, dan data sekunder yang diambil dari Internet, BPS dan Majalah. Data penelitian adalah bulanan, dari Januari 2016 sd Desember 2018. Data dianalsis dengan menggunakan regresi yang dihitung lewat proram time seires processor. Model regresi yang digunakan dengan koreksi kesalahan (error correction model). Model dinamis ini dipandang sebagai sebuah model yang secara praktis dapat mengatasi permasalahan regresi lancung yang sering muncul dalam analisis runtun waktu. Model dalam penelitian ini mengadopsi model Dipack and Thompson's model (1996) dimana secara matematis dapat ditulis sebagai berikut:

$$
\mathrm{Y}_{\mathrm{i}} \quad=\alpha_{0}+\beta_{0} \mathrm{X}_{\mathrm{i}}+\beta \mathrm{X}_{2}+\beta \mathrm{X}_{3}+\beta \mathrm{X}_{4}+\mu \mathrm{t} \ldots \ldots \ldots \ldots \ldots \ldots \ldots \ldots \ldots
$$


Lebih lanjut, model diatas diadopsi kedalam model koreksi kesalahan menjadi:

$$
\begin{aligned}
\text { DLY }_{\mathrm{t}}= & \mathrm{c}_{0}+\mathrm{d}_{1} \mathrm{DLP}_{\mathrm{t}}+\mathrm{d}_{2} \mathrm{DLH}_{\mathrm{t}}+\mathrm{d}_{3} \mathrm{DLA}_{\mathrm{t}}+\mathrm{d}_{4} \mathrm{DLL}_{\mathrm{t}}+\mathrm{d}_{5} \mathrm{BLP}_{\mathrm{t}-1}+ \\
& \mathrm{d}_{6} \mathrm{BLH}_{\mathrm{t}-1}+\mathrm{D}_{7} \mathrm{BLA}_{\mathrm{t}-1}+\mathrm{D}_{8} \mathrm{BLL}_{\mathrm{t}-1}+\mathrm{D}_{9} \mathrm{ECT} \ldots \ldots \ldots \ldots \ldots \ldots \ldots \ldots \ldots \ldots
\end{aligned}
$$

Keterangan penanda:

$\mathrm{Y}=$ Total Penjualan Cerutu PT BIN; $\mathrm{P}=$ Produk Cerutu PT BIN

$\mathrm{H}=$ Harga Rata-rata Cerutu PT BIN; A = Biaya Pemasaran Cerutu PT BIN

$\mathrm{L}=$ Biaya Pemasaraan Cerutu PT BIN

Dimana:

$\mathrm{DLY}_{\mathrm{t}}=\mathrm{L}_{\mathrm{n}} \mathrm{Y}-\mathrm{L}_{\mathrm{n}} \mathrm{Y}(-1) ; \mathrm{DLP}_{\mathrm{t}}=\mathrm{L}_{\mathrm{n}} \mathrm{P}-\mathrm{L}_{\mathrm{n}} \mathrm{P}(-1) ; \mathrm{DLH}_{\mathrm{t}}=\mathrm{L}_{\mathrm{n}} \mathrm{H}-\mathrm{L}_{\mathrm{n}} \mathrm{H}(-1) ; \mathrm{DA}_{\mathrm{t}}=$ $\mathrm{L}_{\mathrm{n}} \mathrm{A}-\mathrm{L}_{\mathrm{n}} \mathrm{A}(-1) ; \mathrm{DLL}_{\mathrm{t}}=\mathrm{L}_{\mathrm{n}} \mathrm{A}-\mathrm{L}_{\mathrm{n}} \mathrm{A}(-1)--\mathrm{BLP}_{\mathrm{t}}=\mathrm{L}_{\mathrm{n}} \mathrm{P}(-1) ; \mathrm{BLH}_{\mathrm{t}}=\mathrm{L}_{\mathrm{n}} \mathrm{H}(-1)$; $\mathrm{BLA}_{\mathrm{t}}=\mathrm{L}_{\mathrm{n}} \mathrm{A}(-1) ; \mathrm{BLL}_{\mathrm{t}}=\mathrm{L}_{\mathrm{n}} \mathrm{L}(-1)--\mathrm{ECT}=\mathrm{L}_{\mathrm{n}} \mathrm{P}(-1)+\mathrm{L}_{\mathrm{n}} \mathrm{H}(-1)+\mathrm{L}_{\mathrm{n}} \mathrm{D}(-1)+\mathrm{L}_{\mathrm{n}} \mathrm{A}$ $(-1)-L_{n} X \quad(-1)$

Dari persamaan dua di atas, selanjutnya kita dapat menurunkan bentuk model koreksi kesalahan jangka pendek tersebut ke dalam bentuk model koreksi kesalahan jangka panjang sebagai berikut:

$$
\mathrm{L}_{\mathrm{n}} \mathrm{Y}_{\mathrm{t}} \quad=\mathrm{d}_{0}+\mathrm{e}_{1} \mathrm{~L}_{\mathrm{n}} \mathrm{P}_{\mathrm{t}}+\mathrm{e}_{2} \mathrm{~L}_{\mathrm{n}} \mathrm{H}_{\mathrm{t}}+\mathrm{e}_{3} \mathrm{~L}_{\mathrm{n}} \mathrm{A}_{\mathrm{t}}+\mathrm{e}_{4} \mathrm{~L}_{\mathrm{n}} \mathrm{L}_{\mathrm{t}} \ldots \ldots \ldots \ldots \ldots
$$

Keterangan penanda:

$\mathrm{d}_{0}=\left(\mathrm{c}_{0} / \mathrm{d}_{9}\right) ; \mathrm{e}_{1}=\left(\mathrm{d}_{5}+\mathrm{d}_{9}\right) / \mathrm{d}_{9} ; \mathrm{e}_{2}=\left(\mathrm{d}_{6}+\mathrm{d}_{9}\right) / \mathrm{d}_{9} ; \mathrm{e}_{3}=\left(\mathrm{d}_{7}+\mathrm{d}_{9}\right) / \mathrm{d}_{9} ; \mathrm{e}_{3}=\left(\mathrm{d}_{8}+\mathrm{d}_{9}\right) / \mathrm{d}_{9}$

\section{Hasil Dan Pembahasan}

\section{Analisis dan Interpretasi}

Dengan menggunakan data bulanan dari 2016.1 - 2018.12, diperoleh hasil regresi dengan model koreksi kesalahan sebagai berikut:

$$
\begin{aligned}
& \mathrm{DLY}=11.05+1.77 \mathrm{DLP}-0.27 \mathrm{DLH}+0.20 \mathrm{DLA}+1.09 \mathrm{DLL} \\
& \begin{array}{llll}
(2.02) \quad(2.14) \quad(-2.27) \quad(1.54) \quad(1.35)
\end{array} \\
& -0.24 \mathrm{BLP}-0.89 \mathrm{BLH}-0.92 \mathrm{BLA}+0.34 \mathrm{BLL}+0.79 \mathrm{ECT} \\
& \begin{array}{llll}
(2.14) \quad(-2.27) \quad(1.04) \quad(0.97) \quad(3.79)
\end{array} \\
& \mathrm{R}^{2}=0.53 \quad \text { D-W stat }=1.95 \quad \text { F-stat }=3.20
\end{aligned}
$$

Jika nilai tersebut disajikan dalam bentuk persamaan jangka panjang, maka akan tampak seperti persamaan berikut ini:

$$
L_{n} Y=13.98+0.69 L_{n} P-0.12 L_{n} H+0.16 L_{n} A+1.43 L_{n} L
$$

Dalam bentuk logaritma persamaan diatas dapat ditulis kembali menjadi:

$\log \mathrm{Y}=13.98+\log \mathrm{P}^{0.69}-\log \mathrm{H}^{0.12}+\log \mathrm{A}^{0.16}+\log \mathrm{L}^{1.43}$

Dengan menganggap bahwa hasil estimasi ECM di atas dihasilkan 
transformasi Koyck, maka dapat dikemukakan bahwa besarnya nilai tingkat penurunan (rate of decline) adalah $\mathrm{b}_{9}(\mathrm{ECT})=0,78$ dan mean lag adalah $\left[\mathrm{b}_{9} /(1-\right.$ $\left.\left.\mathrm{b}_{9}\right)\right]=[0.78 /(1-0.78)]=3.54$. Ini berarti bahwa sekitar 78,00 persen dari gap akan tertutup dalam satu periode dengan kecepatan $\mathrm{L}_{\mathrm{n}} \mathrm{X}$ dalam merespons perubahan $\mathrm{L}_{\mathrm{n}} \mathrm{P}, \mathrm{L}_{\mathrm{n}} \mathrm{H}, \mathrm{L}_{\mathrm{n}} \mathrm{A}$ dan $\mathrm{L}_{\mathrm{n}} \mathrm{L}$ sebesar 4 bulan.

\section{Interpretasi}

Untuk menginterpretasi koefisien variabel dalam penelitian ini, analisis akan menggunakan model 5, karena inti dari analisis regresi dimaksudkan untuk memahami perilaku variabel ekonomi dalam jangka panjang.

\section{a. Produk}

Nilai koefisien variabel jumlah varian produk adalah 0.69. Angka koefisien ini mencerminkan tingkat elastisitas jumlah varian produk terhadap permintaan cerutu BIN di pasar lokal. Nilai koefisien variabel ini kurang dari satu, dapat dikatakan bahwa hubungan antara variabel varian produk dan nilai total penjualan cerutu BIN di pasar lokal berkorelasi positif dan inelastik. Secara ekonomi, angka koefisien (atau tingkat elastisitas) ini menunjukkan bahwa apabila jumlah varian produk meningkat/ lebih banyak 1 persen, akan berakibat pada kenaikan penjualan cerutu BIN di pasar lokal sebesar 0,69 persen.

Hasil analsis ini sesuai dengan teori pemasaran yang menjelaskan bahwa apabila perusahan menambah variaran produk maka permintaan akan bertambah, karena konsumen memiliki lebih banyak referensi atau pilihan produk. Teori ini berlaku pada produk cerutu BIN yang dipasarkan di Indonesia. Penambahan jumlah varian produk yang dilakukan oleh BIN sangat membantu peningkatan omset penjualan mereka. Pihak manajemen menjelaskan selama kurun waktu tiga tahun, BIN telah berhasil melakukan inovasi produk mereka sehingga varian cerutu menjadi lebih banyak. Jika pada tahun 2016 jumlah varian produk cerutu BIN sebanyak 17 jenis, pada tahun 2017 dan 2018 masing-masing varian produk meningkat menjadi 23 dan 29 jenis. Keberhasilan dalam menciptakan produk baik sisi ukuran (size), model, kemasan dan terutama “taste” yang dilakukan secara terus menerus oleh BIN telah mengantarkan perusahaan ini menjadi semakin terkenal di pasar cerutu lokal dan internasional. 
Disamping itu, manajemen juga mengakui bahwa kosistensi dalam menjaga kualitas produk pada masing-masing varian, terutama produk yang sudah sangat diminati oleh penikmat cerutu seperti marek robusto, corona dan el nino selalu dijaga. Dan bahkan produk tersebut diberikan kemasan khusus sehingga dapat menambah daya tarik dan kepuasan konsumen. Konsistensi rasa "cuba" yang dimiliki oleh cerutu BIN sangat kuat, dan mampu mengantarkan produk mereka hampir setara dengan kualitas cerutu yang dipeoduksi perusahaan terkenal dunia.

\section{b. Harga}

Nilai koefisien variabel harga cerutu BIN adalah -0.12. Angka koefisien ini mencerminkan tingkat elastisitas harga rata-rata cerutu BIN di pasar lokal. Oleh karena nilai koefisiennya kuran dari satu, dapat dikatakan bahwa hubungan antara variabel harga dan nilai total penjualan cerutu BIN berkorelasi negatif dan inelastik. Secara ekonomi, angka koefisien (atau tingkat elastisitas) ini menunjukkan bahwa apabila harga rata-rata cerutu BIN meningkat 1 persen, akan berakibat pada penurunan nilai total penjualan cerutu BIN di pasar lokal sebesar 0,12 persen.

Kondisi ini sesuai dengan teori the law of demand menyatakan bahwa apabila harga suatu produk meningkat, dengan asumsi cateris paribus, akan menurunkan permintaan produk itu sendiri. Teori ini berlaku pada produk cerutu BIN di pasar lokal yang menjelaskan bahwa kenaikan harga akan menurunkan nilai pejualannya. Hal yang menarik untuk dicermati dari nilai koefisien adalah angka inelastik pada variabel ini. Secara teori, apabila nilai koefiien inelastik, perusahaan dapat mengambil kebijakan menaikkan harga. Kebijakan ini bisa dilakukan karena dengan menaikkan harga 1 persen, meskipun terjadi penurunan penjualan 0.12 persen, akan meningkatkan laba perusahaan. Bagi konsumen, cerutu BIN adalah merupakan specialty product. Terdapat dua alasan yang dapat memperkuat strategi kenaikan harga cerutu BIN di pasar lokal. Dua alasan tersebut adalah (1) harga cerutu BIN relatif lebih murah dibandingkan pesaing denkatnya seperti cerutu Bobbin dan perusahaan cerutu lain (2) permintaan produk cerutu BIN terus meningkat karena didukung oleh inovasi produk.

\section{c. Biaya Iklan}

Nilai koefisien biaya iklan terhadap penjualan cerutu BIN di pasar lokal 
adalah 0.16. Angka koefisien ini mencerminkan tingkat elastisitas biaya iklan terhadap total penjualan cerutu BIN di pasar lokal. Namun demikian, berdasarkan perhitungan statistik varibel ini tidak signifikan pada tingkat keyakinan $\alpha 5$ persen. Hasil statistik ini tidak sesuai dengan teori yang ada yang menyatakan bahwa biaya iklan berpengaruh positif terhadap penjualan cerutu BIN di pasar lokal. Dengan kata lain, biaya iklan tidak memberikan dampak pada jumlah penjualan cerutu BIN. Alasan yang paling kuat kenapa biaya iklan tidak berpengaruh signifikan terhadap penjualan cerutu BIN karena metode iklan hanya terkonsentarsi pada sponsorsip saja. Marketing perlu mempertimbangkan metode periklanan yang lain seperti media cetak, telivisi dan mengoptimalkan media sosial yang lain. Pameran-pameran cerutu yg diselenggarakan di tingkat nasional dan internasional juga perlu diikuti supaya BIN lebih dikenal luas, meskipun harus merogoh kocek yang lebih besar.

Dilihat dari data yang ada selama periode pengamatan menunjukkan bahwa jumlah biaya iklan masih relatif kecil dan bahkan menurun. Jika pada tahun 2016 biaya iklan sebesar Rp. 89.000.000, pada tahun 2017 menurun menjadi Rp. 63.000.000 dan pada tahun 2018 biaya iklan menurun lagi menjadi Rp. 56.300.000. Diakui oleh manajemen BIN yang mengatakan bahwa biaya iklan yang menurun dikarenakan pemerintah semakin memperketat dan membatasi iklan rokok. Hal ini dilakukan oleh pemerintah untuk mengurangi jumlah perokok di Indonesia.

\section{d. Saluran Distribusi}

Nilai koefisien variabel saluran distribusi adalah 1.43. Angka koefisien ini mencerminkan tingkat elastisitas saluran distribusi terhadap total penjualan cerutu BIN di pasar lokal. Oleh karena nilai koefisiennya lebih dari satu, dan merupakan variabel independen yang memiliki tingkat elastisitas paling tinggi, dapat dikatakan bahwa hubungan antara variabel saluran distribusi dan nilai total penjualan cerutu BIN di pasar lokal berkorelasi positif dan elastik. Namun demikian sayang, dilihat dari nilai t statistik variabel ini tidak signifikan.

Hasil temuan ini tidak sesuai dengan teori pemasaran yang menyatakan bahwa banyaknnya saluran distribusi akan meningkatkan penjualan suatu produk. Dalam literatur pemasaran, saluran distribusi sangat penting dalam menyalurkan produk perusahan ketangan konsumen. Ada dua alasan yang menyebabkan saluran 
distribusi tidak meningkatkan penjualan cerutu BIN di pasar lokal. Pertama, saluran distribusi yang dimiliki oleh BIN masih sangat sedikit. Dilihat dari data yang ada menunjukkan bahwa saluran distribusi yang dimiliki oleh BIN hanya sebanyak 20 hotel dan 19 agen pada tahun 2016, sedangkan pada tahun 2017 meningkat menjadi 38 hotel dan 34 agen dan pada tahun 2018 sebanyak 58 hotel dan 54 agen. Kedua, saluran distribusi hanya terbatas pada agen dan hotel. Cerutu adalah barang specialty product sehingga perusahaan perlu memperbanyak saluran distribusi, dan kalau perlu merancang distribusi seperti pada barang konfinien.

Dari pembahasan di atas dapat ditarik kesimpulan bahwa variabel marketing mix dalam penelitian ini secara signifikan statistik sangat berpengaruh terhadap nilai total penjualan cerutu BIN di pasar lokal. Hal ini dapat dilihat pada nilai $\mathrm{F}$ statistik 3,20. Meskipun demikian, masih banyak variabel-variabel lain di luar model yang mempengaruhi nilai penjualan cerutu BIN. Faktor-faktor ekonomi dan non-ekonomi terutama variabel yang tidak dapat dikontrol oleh perusahaan di dalam negeri seperti pertumbuhan ekonomi, perubahan struktur pendepatan, reregulasi pemerintah, intensitas persaingan, dan lainnya merupakan bagian dari 47.05 persen dari variabel-variabel yang tidak tercakup dalam penelitian ini. Mengingat, berdasarkan analisis statistik, R-square dari model analisis ini adalah 53.50 persen. Artinya, variabel independen yang masuk dalam model mempengaruhi variasi variabel dependennya hanya sebesar 53.50 persen, sedangkan sisanya (46.50) dipengaruhi oleh variabel-variabel lain diluar model.

\section{Kesimpulan}

Setelah mengetahui hubungan atau pengaruh variabel-variabel ekonomi terhadap total penjualan cerutu BIN di dalam negeri dengan pendekatan model koreksi kesalahan di atas, dapat ditarik kesimpulan sebagai berikut:

1. Jumlah varian produk secara signifikan statistik berpengaruh positif terhadap nilai penjualan cerutu BIN di pasar lokal.

2. Harga rata-rata cerutu secara signifikan statistik berpengaruh negatif terhadap nilai penjualan cerutu BIN di pasar lokal. 
3. Biaya promosi secara signifikan statistik tidak berpengaruh terhadap nilai penjualan cerutu BIN di pasar lokal.

4. Jumlah saluran distribusi secara signifikan statistik tidak berpengaruh positif terhadap nilai penjualan cerutu BIN di pasar lokal..

5. Jumlah varian produk, Harga rata-rata cerutu BIN, Biaya promosi, dan Jumlah saluran distribusi secara signifikan statistik berpengaruh signifikan terhadap nilai penjualan cerutu BIN di pasar lokal.

Berdasarkan hasil analisis kuantitatif dan kualitatif yang diperoleh dari penelitian ini, beberapa rekomendasi di bawah ini dapat dipertimbangkan oleh PT Bos Image Nusantara (BIN)

1. Jumlah varian produk yang diproduksi bisa ditambah secara berkesinambungan. Produk premium yang sudah dicintai oleh penikmat cerutu harus dijaga kualitasnya, dan jika dipelukan menambah vitur kemasan. Ukuran batang produk dan flavor cerutu masih menjadi peluang bagi perusahaan untuk dikembangkan sehingga produk BIN semakin mendapat tempat di hati penggemarnya.

2. Harga rata-rata produk cerutu BIN dapat ditingkatkan. Manajemen perlu jeli mengamati produk cerutu dari jenis/varian mana yg harganya ditingkatkan. Jika suatu harga varian produk dianggap inelastik, perusahaan dapat sedikit melakukan reposisi harga. Tentu reposisi harga ini diikuti oleh penambahan vitur produk. Untuk harga pada suatu varian produk yang elastik, sebaiknya perusahaan tetap mempertahankan harga.

3. Biaya promosi BIN perlu ditingkatkan jumlahnya karena media promosi sangat penting untuk pengingat bagi konsumen yang sudah loyal dengan produknya, dan untuk mengenalkan pada konsumen baru. Berkaitan dengan aturan pemerintah yang membatasi periklanan rokok sebaiknya manajemen perlu memilih media promosi yang cocok, efisien dan efektik dilakukan.

4. Sama halnya dengan variabel promosi, saluran distribusi cerutu BIN supaya diperbanyak jumlahnya. Karena cerutu sebagai produk spesial membutuhkan lebih banyak distribution channel. Konsentarsi pemasaran yang semula pada pulau Jawa dan Bali perlu di tambah. Misalnya dengan membagi area 
pemasaran ke wilayah timur (papua, sulawesi, bali), tengah (jawa, kalimantan, maluku) dan barat (sumatera).

\section{DAFTAR PUSTAKA}

Aliman, (2000), Modul Ekonometrika Terapan, PAU STUDI EKONOMI, Universitas Gadjah Mada, Jogjakarta

Ebert, Ronal J., dan Griffin, Ricky W. 2000, Busniess Essential, International Edition, Third Edition, Upper Saddle River, New Jersey, Prentice Hall Inc Gujarati, Damodar (1995), Basic Econometrics, McGraw-Fill, Inc. USA

Gunawan W, Pater, 2017. Analisis Segmenting, Targeting, Positioning dan Marketing Mix pada PT Murni Jaya, Agora Vol 5 No 1, Universitas Kristen Petra, Surabaya

Insukindro, (1993), Pemilihan Model Ekonomi Empirik dengan Pendekatan Koreksi Kesalahan, JEBI, FE UGM, Jogjakarta

Irsad Z, 2010, Analisis Marketing Mix (product, price, promotion and place) yang Memengaruhi Kepuasan Pelanggan Pengguna Operator ESIA' Studi Kasus pada Masyarakat Ciputat Timur, Skripsi, FEB Syarif Hidayatullah

Krugman, Paul R and Obstfeld, Maurice (1999), International Economic: Theory and Policy, HarperCollins Publisher. Fifth edition, USA

Phillip Kotler, (2003), Marketing Management, United State of America: New Jersey, Prentice Hall. Inc

Kotler, Philipe and Gary Amstrong, (2004), Principle of Marketing, Prentice Hall, $10^{\text {th }}$ ed, Englewood Cliffs, New Jersy

Rugman, Alan M, et al (1987), International Business: Firm and Environment, McGRAW-HILL BOOK COMPANY, USA

Swastha, Basu., D.H., dan Irawan, (2000), Manajemen Pemasaran Modern, Edisi Kedua, Cetakan ke Empat, Liberty Jogjakarta

Tjiptono, Fandi, 2001, Strategi Pemasaran, Edisi 1, Andi Offset, Yogyakarta 
Relasi : Jurnal Ekonomi, Vol. 16, No. 1, Januari 2020, hlm. 54-74 